\title{
Effect of Montelukast on Elderly Patients with Bronchial Asthma and Its Effect on Serum Transforming Growth Factor- $\beta 1$ and Cysteine Leukotriene Levels
}

\author{
J. REN, XIAOMENG LI ${ }^{1}$, L. WANG, MINGZHU LIU, KE ZHENG AND YANRONG WANG*
}

Central Hospital of Shanghai Jingan District, Shanghai 200040, ${ }^{1}$ Endoscopy Center of China Japan Union Hospital to Jilin University, Changchun 130033, P. R. China

Ren et al.: Effect of Montelukast on Elderly Patients with Bronchial Asthma

\begin{abstract}
To investigate the effect of montelukast on elderly patients with bronchial asthma and the effects of serum transforming growth factor $\beta 1$ and cysteinyl leukotriene, 150 patients with bronchial asthma enrolled in the Central Hospital of Shanghai Jingan District between October 2016 to October 2018, and those who met the clinical diagnostic criteria were included. All patients were given antispasmodic and antiinfective treatment after admission. The study group (75 cases) were administered orally montelukast chewable tablets, while the control group (75 cases) was not given montelukast. Comparison of the efficacy of the two groups and lung function indicators before and after treatment, such as 1 second forced expiratory volume, first second forced expiratory volume versus forced vital capacity ratio (1 second forced expiratory volume/versus forced vital capacity), first second forced expiratory volume as predicted percentage and changes in the levels of serum transforming growth factor- $\beta 1$ and cysteinyl leukotriene. The effective rate of treatment in the study group was higher than that in the control group $(93.33 \mathrm{vs} .78 .67 \%$, p<0.05). The first second forced expiratory volume, 1 second forced expiratory volume/versus forced vital capacity and percentage of first second forced expiratory volume/predicted of the study group were significantly increased after treatment $(p<0.05)$, and higher than those of the control group $(p<0.05)$. The levels of transforming growth factor- $\beta 1$ and cysteinyl leukotriene in the study group were significantly decreased before treatment $(p<0.05)$, and were lower than those in the control group $(p<0.05)$. Montelukast treatment of bronchial asthma in the elderly can significantly improve lung function and improve clinical outcomes. Its mechanism of action may be related to the reduction of transforming growth factor $\beta 1$ and cysteinyl leukotriene levels.
\end{abstract}

Key words: Montelukast, old age, bronchial asthma, TGF- $\beta 1$, Cys-LTs

Bronchial asthma is a chronic allergic disease of the airway. If asthma cannot be effectively relieved for a long time, it can lead to irreversible airway obstruction, poor remodelling, and decreased elasticity of alveoli, emphysema and even heart disease ${ }^{[1]}$. The elderly patients are often accompanied by osteoporosis, hypertension, diabetes and other basic diseases. The diagnosis and treatment of elderly bronchial asthma has been a big problem in the medical field. Airway inflammation is the main pathogenesis of bronchial asthma. Transforming growth factor- $\beta 1$ (TGF- $\beta 1$ ) and cysteine leukotriene (CysLT) are the main mediators of chronic airway inflammation and airway remodelling. These are also markers of inflammatory reaction and play an important role in the pathogenesis of bronchial asthma $^{[2-3]}$. Montelukast is a blocker of leukotriene (LT) receptor, which has a significant effect on the treatment of asthma ${ }^{[4]}$.

Inclusion criteria were, all patients in the group met the diagnostic criteria in the guidelines for the prevention and treatment of bronchial asthma ${ }^{[5]}$. All patients and their families agreed and signed the informed consent. No history of major diseases such as heart disease, liver and kidney dysfunction, tumour, and drug and food allergy. Exclusion criteria were, patients with serious haematological and immunological dysfunction. Patients who have used immunomodulators, glucocorticoids or this study drug in the past $1 \mathrm{mo}$. Patients with chronic liver and kidney diseases, severe protein energy malnutrition and congenital lung diseases. Those that do not cooperate with the treatment. One hundred and fifty patients were enrolled 
and were divided into the control group and the study group randomly. The baseline data of age, gender and course of disease of the two groups were comparable ( $\mathrm{p}>0.05)$, as shown in Table 1. This study was approved by the ethics committee of our hospital.

All patients were given symptomatic support treatment after admission, including the treatment of oxygen inhalation, antiinfective therapy, antispasmodic and antiasthmatic drugs. In the study group, oral montelukast was added to the basic treatment, $10 \mathrm{mg}$ once a day for $28 \mathrm{~d}$. Control group received only basic treatment, but not montelukast. Clinical effects were categorised as significant effect if the clinical symptoms such as lung wheeze, wheeze cough and wheeze basically disappeared, first second forced expiratory volume (FEV1) increased by more than $35 \%$ in the first second or FEV1 reached the expected value of $80 \%$. Effective is when clinical symptoms such as lung wheeze and wheeze cough and wheeze decreased significantly, FEV1 increased by $25-35 \%$ or FEV1 reached the expected value of $60-79 \%$. Ineffective is when there was no improvement in lung wheeze and wheeze cough or aggravation of clinical symptoms such as cough and wheezing, but no improvement in the decreased FEV1. Clinical effective rate $=$ significant + effective.

According to the American Thoracic Association lung function examination operation specification, the first second forced expiratory volume, the ratio of FEV1 to forced vital capacity (FEV1/FVC), and the percentage of FEV1 to the expected value (PEV1/PRED) were measured. Five millilitres of fasting venous blood was collected in the morning before and after treatment. The supernatant was centrifuged at $3000 \mathrm{rpm}$ in an Eppendorf 5810 centrifuge (Germany) for $10 \mathrm{~min}$ and then frozen at $-70^{\circ}$ in a Sanyo refrigerator (Japan). The levels of TGF- $\beta 1$ and CysLT were measured using enzyme-linked immunosorbent assay. Adverse reactions of the two groups were monitored during the treatment. SPSS25.0 is used for data analysis. The measurement data with homogeneity and normality of variance tested by K-S method are represented by $\mathrm{t}$ test. Rate (\%) indicates that the counting data is tested by 2 , and the grade data is tested by Kruskal Wallis $\mathrm{H}$. $\mathrm{p}<0.05$ : the difference was statistically significant.

The effective rate of treatment in the study group was higher than that in the control group $(\mathrm{p}<0.05)$, as shown in Table 2. There was no difference in FEV1, FEV1/ FVC and PEV1/PRED between the two groups before treatment $(\mathrm{p}>0.05)$. After treatment, FEV1, FEV1/FVC and PEV1/PRED increased $(\mathrm{p}<0.05)$. After treatment, FEV1, FEV1/FVC and PEV1/PRED in the study group were higher than those in the control group $(\mathrm{p}<0.05)$, as shown in Table 3. There was no difference in serum TGF- $\beta 1$ and Cys lts levels between the two groups before treatment $(p>0.05)$. After treatment, the serum TGF- $\beta 1$ and CysLT levels decreased $(p<0.05)$. After treatment, the serum TGF- $\beta 1$ and CysLT levels in the study group were lower than those in the control group $(p<0.05)$, as shown in Table 4 . There was no obvious damage of liver and kidney function and no drugrelated adverse reactions.

\section{TABLE 1: PATIENT GENERAL INFORMATION}

\begin{tabular}{lcccc}
\hline Project & $\begin{array}{c}\text { Research } \\
\text { Group (75) }\end{array}$ & $\begin{array}{c}\text { Control } \\
\text { group (75) }\end{array}$ & t/ $\chi^{2}$ & P \\
\hline Gender (\%) & & & & \\
Male & $41(54.67)$ & $45(60.00)$ & 0.436 & 0.509 \\
Female & $34(45.33)$ & $30(40.00)$ & & \\
Age (y) & $66.82 \pm 5.61$ & $65.02 \pm 6.93$ & 1.748 & 0.082 \\
Course of disease & $3.15 \pm 1.09$ & $3.27 \pm 1.28$ & 0.618 & 0.537 \\
(y) & & & & \\
Asthma grading & & & & \\
Light & $43(57.33)$ & $44(58.67)$ & 0.027 & 0.869 \\
Moderate & $32(42.67)$ & $31(41.33)$ & & \\
\hline
\end{tabular}

TABLE 2: PERCENT CLINICAL EFFECTS

\begin{tabular}{|c|c|c|c|c|c|}
\hline Group & Case & $\begin{array}{l}\text { Markedly } \\
\text { effective }\end{array}$ & Effective & Ineffective & $\begin{array}{c}\text { Total } \\
\text { effective }\end{array}$ \\
\hline $\begin{array}{l}\text { Study } \\
\text { Group }\end{array}$ & 75 & $45(60.00)$ & $\begin{array}{c}25 \\
(33.33)\end{array}$ & $5(6.67)$ & $\begin{array}{c}70 \\
(93.33)\end{array}$ \\
\hline $\begin{array}{l}\text { Control } \\
\text { group }\end{array}$ & 75 & $29(38.67)$ & $\begin{array}{c}30 \\
(40.00)\end{array}$ & $16(21.33)$ & $\begin{array}{c}59 \\
(78.67)\end{array}$ \\
\hline$\chi^{2}$ & & & & & 6.700 \\
\hline$P$ & & & & & 0.010 \\
\hline
\end{tabular}

TABLE 3: THE DIFFERENCE OF FEV1, FEV1/FVC AND PEV1/PRED BETWEEN THE TWO GROUPS BEFORE AND AFTER TREATMENT

\begin{tabular}{|c|c|c|c|c|c|c|c|c|c|c|}
\hline & \multicolumn{4}{|c|}{ Research group (75 cases) } & \multicolumn{4}{|c|}{ Control group (75 cases) } & \multirow[b]{2}{*}{ P1 } & \multirow[b]{2}{*}{ P2 } \\
\hline & $\begin{array}{c}\text { Before } \\
\text { treatment }\end{array}$ & $\begin{array}{c}\text { After } \\
\text { treatment }\end{array}$ & $\mathrm{t}$ & $\mathbf{P}$ & $\begin{array}{c}\text { Before } \\
\text { treatment }\end{array}$ & $\begin{array}{c}\text { After } \\
\text { treatment }\end{array}$ & $\mathrm{t}$ & $\mathbf{P}$ & & \\
\hline $\begin{array}{l}\text { FEV1 (L) } \\
\end{array}$ & $1.53 \pm 0.69$ & $1.95 \pm 0.53$ & 4.181 & 0.000 & $1.55 \pm 0.71$ & $1.80 \pm 0.21$ & 2.924 & 0.004 & 0.861 & 0.024 \\
\hline FEV1/FVC (\%) & $56.92 \pm 13.67$ & $72.52 \pm 15.82$ & 6.462 & 0.000 & $59.05 \pm 13.06$ & $66.13 \pm 14.34$ & 3.161 & 0.002 & 0.331 & 0.011 \\
\hline $\begin{array}{l}\text { PEV1/PRED } \\
\text { (\%) }\end{array}$ & $49.53 \pm 10.25$ & $65.26 \pm 17.67$ & 6.669 & 0.000 & $50.06 \pm 11.64$ & $58.26 \pm 15.43$ & 3.674 & 0.000 & 0.768 & 0.011 \\
\hline
\end{tabular}

Note: P1 is the statistical value of the two groups before treatment; P2 is the statistical value of the two groups after treatment 
TABLE 4: THE DIFFERENCE OF SERUM TGF- $\beta 1$ AND CysLT BETWEEN THE TWO GROUPS BEFORE AND AFTER TREATMENT

\begin{tabular}{lccccccccccc}
\hline & \multicolumn{3}{c}{ Research group (75 cases) } & \multicolumn{3}{c}{ Control group (75 cases) } \\
\cline { 2 - 8 } Target & $\begin{array}{c}\text { Before } \\
\text { treatment }\end{array}$ & $\begin{array}{c}\text { After } \\
\text { treatment }\end{array}$ & $\mathbf{t}$ & $\mathbf{P}$ & $\begin{array}{c}\text { Before } \\
\text { treatment }\end{array}$ & $\begin{array}{c}\text { After } \\
\text { treatment }\end{array}$ & $\mathbf{t}$ & $\mathbf{P}$ & $\mathbf{P 1}$ & $\mathbf{P 2}$ \\
\hline TGF-B1 $(\mathrm{pg} / \mathrm{ml})$ & $146.25 \pm 43.98$ & $70.25 \pm 29.34$ & 12.449 & 0.000 & $147.13 \pm 45.25$ & $95.36 \pm 32.64$ & 8.036 & 0.000 & 0.904 & 0.000 \\
Cys-LT $(\mathrm{pg} / \mathrm{ml})$ & $185.25 \pm 35.61$ & $102.35 \pm 16.54$ & 18.285 & 0.000 & $186.29 \pm 35.69$ & $126.35 \pm 29.67$ & 11.184 & 0.000 & 0.858 & 0.000 \\
\hline
\end{tabular}

Note: $\mathrm{P} 1$ is the statistical value of the two groups before treatment; P2 is the statistical value of the two groups after treatment

Bronchial asthma is characterized by airway hyper responsiveness, which is involved by many kinds of cells and cell components. The patients often show a wide range of reversible symptoms such as airflow restriction, wheezing, shortness of breath, chest tightness and/or cough ${ }^{[6]}$. Bronchial asthma is a common chronic respiratory disease in the world. With the aggravation of environmental pollution, the incidence of bronchial asthma is increasing, which has become a global public health problem ${ }^{[7]}$. Asthma is a widespread and reversible airway stenosis disease caused by allergens or other factors. It can attack within minutes and last for hours to days. Bronchodilators are effective or can relieve themselves. The pathogenesis of bronchial asthma is still unclear. The existing research considers that asthma is a disease with family aggregation tendency and polygenic heritage background ${ }^{[8]}$. The disorder of airway autonomic nerve function is the pathophysiological basis leading to airway hyper responsiveness ${ }^{[9]}$. Inflammatory mediators, EOS, mast cells, living platelets, all participate in the formation of airway inflammation.

TGF- $\beta 1$ is a multifunctional cell regulatory factor. In the pathological process of asthma, TGF- $\beta 1$ can be used as an inflammatory factor to start the chronic inflammatory response of the airway, promote the mitosis and proliferation of airway fibrocytes, cause airway fibrosis and remodelling, and aggravate asthma ${ }^{[10]}$. LT is an important inflammatory factor, which can promote the synthesis and release of inflammatory cytokines. It tends to infiltrate and activate inflammatory cells in the airway, forming chronic airway inflammation, causing the contraction of bronchial smooth muscle and promoting the inflammatory response. Previous studies have shown that CysLT participates in the airway inflammation of asthma ${ }^{[11]}$. The levels of TGF- $\beta 1$ and LTE4 are closely related to the severity of asthma in children with acute attack. They are important observation indexes for clinical monitoring of asthma, evaluation of curative effect and judgment of prognosis ${ }^{[12]}$.
Montelukast is a highly effective and selective LT receptor antagonist. By combining with LT receptor in airway smooth muscle cells, montelukast can block the production of LT polypeptide, improve airway permeability, increase mucus secretion, inhibit eosinophil and basophil infiltration, reduce airway inflammation, high reactivity and remodelling, improve lung function and alleviate asthma symptoms ${ }^{[13]}$. Existing research shows that montelukast can effectively reduce the level of LT's in children with asthma, control the acute attack of asthma, and reduce the recurrence ${ }^{[14,15]}$. This study shows that montelukast has a reliable clinical effect in the treatment of elderly bronchial asthma, which is superior to the basic treatment, and can significantly improve the lung function of patients. During the treatment, there is no serious drug-related adverse reaction, and the safety is high. In this study, we observed the effect of montelukast on the levels of TGF- $\beta 1$ and CysLT, and found that montelukast has a good inhibitory effect on the levels of TGF- $\beta 1$ and CysLT, suggesting that montelukast may play a role in the treatment of asthma by inhibiting the levels of TGF- $\beta 1$ and CysLT. However, the specific mechanism still needs further clinical research.

In summary, montelukast treatment of elderly patients with asthma can significantly improve lung function and improve clinical efficacy. The mechanism may be related to the decrease of TGF- $\beta 1$ and CysLT. Since no further mechanism study has been carried out in this study, the mechanism of montelukast in the treatment of bronchial asthma remains to be confirmed by more clinical studies.

\section{Conflict of interest:}

There was no conflict of interest.

\section{REFERENCES}

1. Srinivasa K, Ushakiran B, Rudrappa S. Clinical study of bronchial asthma in children aged 5 to 12 years with special reference to peak expiratory flow rate. Int J Contemp Pediatr 2015;4:297-302.

2. Yin WM, Li FX, Wei CZ. Study on the correlation between pulmonary function and leukotriene level in adult asthma 
patients with chronic persistence. J Clin Pathol 2015;35:148792.

3. Gu P, Chen JL, Chen JR. Detection and significance of IL-13 and TGF- $\beta 1$ in exhaled air condensate of patients with asthma. J Practical Clinical Med 2017;23:215-6.

4. Zhu NQ. Clinical efficacy analysis of montelukast sodium in the treatment of childhood asthma. Jilin Med 2015;10:2095.

5. Asthma group, respiratory branch, Chinese Medical Association. Guidelines for the prevention and treatment of asthma. Chin J Tuberc Res 2008:31:177-89.

6. He JM, Li XR, Li FH. Epidemiological observation and risk factor analysis of bronchial asthma. J Shanxi Med Univ 2015;12:1224-27.

7. Liang SH, Zhao HT, Li SU, Zhang ZY, Zhang JL, Yang HY, et al. Epidemiological investigation and analysis of bronchial asthma in combat troops garrisoned in the cold areas of northeast China. Med J Chin People's Liberation Army 2016;41:327-31.

8. Shahid M, Sabar MF, Bano I, Rahman Z, Iqbal Z, Fatim Ali $\mathrm{SS}$, et al. Sequence variants on $17 \mathrm{q} 21$ are associated with the susceptibility of asthma in the population of Lahore, Pakistan. J Asthma 2015;52:777-84.

9. Liu DQ, Yan SS, Dai YR. Nerve growth factor and its research progress in bronchial asthma. Int J Res 2015;35:202-5.

10. Song XH. Airway smooth muscle cells and airway remodeling in asthma. Int J Contemp Pediatrics 2015;42:156-8.
11. Chen HZ, Ji QM, Li L. The clinical efficacy of montelukast in the treatment of moderate to severe stable chronic obstructive pulmonary disease and the role of leukotriene E4. J Modern Integrated Chin West Med 2016;25:2675-78.

12. Su LS. Changes of serum IL-4, IFN - $\gamma$, no and TGF - $\beta 1$ levels in asthmatic children and their clinical significance. Chin Mat Child Health Care 2018;1:100-2.

13. Wen H. Effects of montelukast on lung function and balance of Th1 and Treg in patients with bronchial asthma. Exp Ther Med 2017;26:1219-21.

14. Lu NN, Cong LL, Zhao Q. Effect of montelukast on serum leukotriene level in children with asthma. Chin Exp Diagnostics 2015;10:1790-92.

15. Zhang XY, Ma LM, Li XM. Clinical study of montelukast in the treatment of cough variant asthma in children. Chin Pharm 2017;28:4103-6.

This is an open access article distributed under the terms of the Creative Commons Attribution-NonCommercial-ShareAlike 3.0 License, which allows others to remix, tweak, and build upon the work non-commercially, as long as the author is credited and the new creations are licensed under the identical terms

This article was originally published in a special issue, "Recent Trends in Biomedical Research" Indian J Pharm Sci 2020:82(1)spl issue1; XX-XX 